\title{
desarrollo y experiencias con blindajes de caucho en molinos de bolas, tubulares, de guijarros o de barras
}

Dipl. Ing. F. MOHR KASSEL

Aufbereitungs-Technik, 8, n.॰ 6, junio 1967, pägs. 325-331

\section{R E S U M E N}

Se describe detalladamente el desarrollo de blindajes de caucho. Es de la mayor importancia establecer un sistema de fijación hermético para el revestimiento del molino, ya que es esencial para lograr unas características de desgaste favorables, empleando la calidad de caucho apropiada. Al mismo tiempo se tratan otras ventajas, tales como la disminución del ruido al emplear blindajes de caucho en vez de acero.

Por último se da un informe detallado sobre el empleo de blindajes de caucho en la práctica, acompañado por muchos cuadros. Puede desprenderse de este informe que el empleo de blindajes de caucho, teniendo en cuenta algunas condiciones previas, resulta extraordinariamente rentable.

\section{DESARROLLO Y CONSIDERACIONES GENERALES}

En los EE.UU., en el año 1923, ya se blindaron con caucho los molinos de bolas y los molinos tubulares. De la literatura técnica y de las patentes puede deducirse que el sistema de fijación era insuficiente y que se utilizaba un caucho de la misma calidad que el de las ruedas de coche.

En el año 1935 se trató otro sistema de fijación parecido que tampoco tuvo éxito técnico ni económico. En ambos casos, la fijación se basaba en que las llamadas barras elevadoras estaban provistas de raíles de acero recubiertas de caucho vulcanizado, según se observa en la figura 1. De esto resultó una fijación rígida y un desgaste extraordinariamente elevado.

El blindaje de caucho, por razones de rentabilidad, no podía competir con el blindaje de acero. El famoso experto de molinos norteamericano, Prof. A. F. Taggart, en su manual Handbook of Mineral Dressing, ed. 1960, dice: "que los blindajes de caucho en los molinos no tienen éxito por la insuficiente fijación del caucho en los mismos". Esta afirmación del Prof. Taggart es completamente correcta. 
Solo por el nuevo sistema de fijación, desarrollado hace algunos años, pudo comprobarse que las clases de caucho resistentes contra la abrasión, bajo ciertas condiciones previas, son más económicas y se gastan menos que el acero. Lo esencial del nuevo sistema de fijación es que las barras elevadoras están empotradas elásticamente según la figura 2. Así se alcanza una extraordinaria resistencia contra el desgaste.

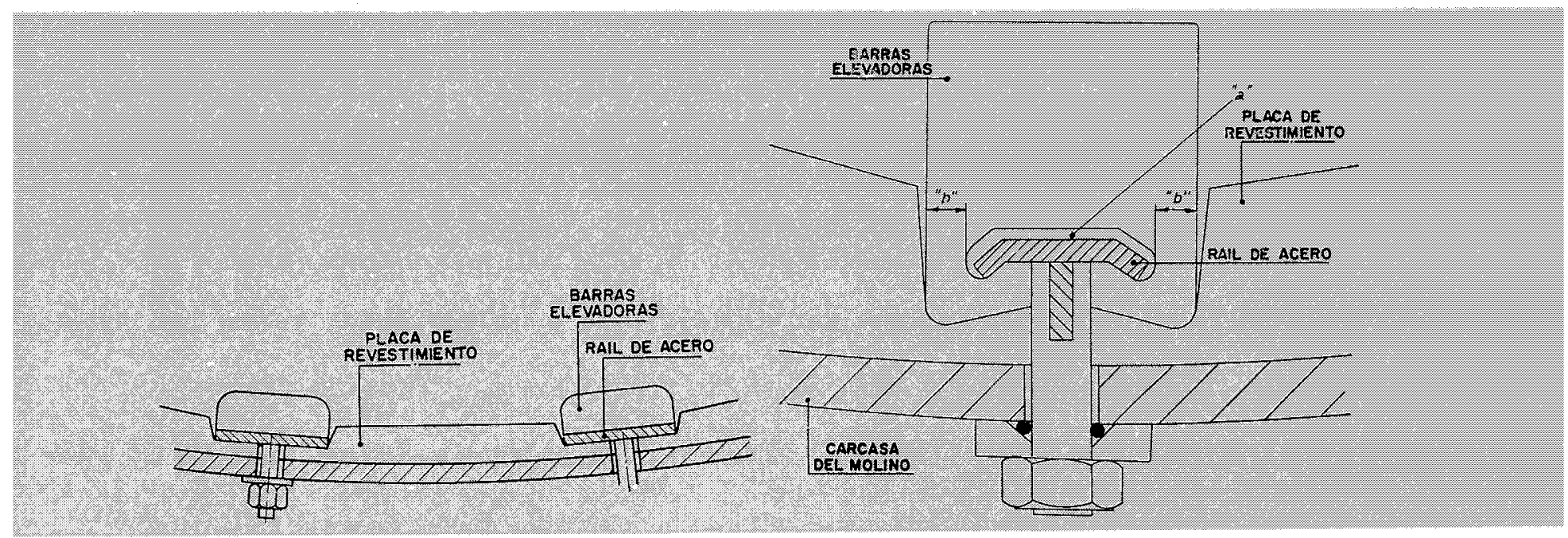

Fig. 1.-Fijación del blindaje de caucho por barras de

Fig. 2.-Fijación elástica del blindaje de caucho acero recubiertas de caucho vuleanizado.

Esta elasticidad se consigue por la abertura "a", que se produce al empotrar el rai\} contra la envoltura del molino y además por las partes "b" relativamente blandas en los dos lados de la abertura.

El dar golpes y forzar la barra elevadora trae como consecuencia que la elasticidad funciona como medio de amortiguación, y la presión sobre el suelo no alcanza en general valores críticos.

Además de un método correcto de fijación, son esenciales para el blindaje de caucho los siguientes factores:

- tipos de caucho que sean especialmente resistentes contra el desgaste deslizante;

- el ángulo de choque del material contra la superficie de desgaste;

- la velocidad de choque contra la superficie de desgaste;

- el perfil del blindaje.

El mayor desgaste se produce en " $A$ " para velocidades que corresponden a un bu$-75 \%$ de la velocidad crítica (véase figura 3 ). Los cuerpos de molienda y el material que se muele sufren un cambio de dirección, $\mathrm{y}$, como consecuencia, se producen turbulencias y un gran desgaste de la superficie.

En ciertos casos el material tropieza contra la superficie de desgaste en un ángulo agudo, por lo cual se origina un desgaste mayor. 
Para evitar empujes en la superficie, el perfil del blindaje tiene que realizarse de tal manera que el material esté frenado elásticamente y de la manera más rápida posible.

Con las velocidades antes mencionadas no se produce una presión crítica empleando como elementos molturadores, p.e. bolas de $70 \mathrm{~mm} \varnothing$ o guijarros de 150 milímetros.

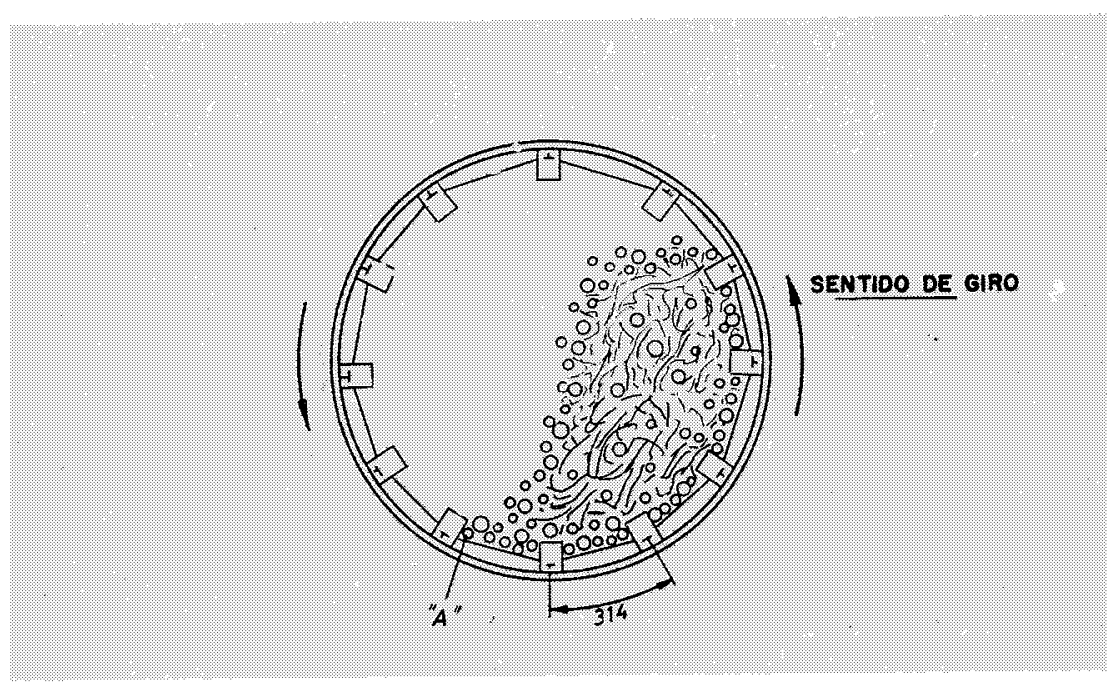

Fig. 3.-Esquema de la trayectoria de la carga de bolas y material en un molino provisto de caucho.

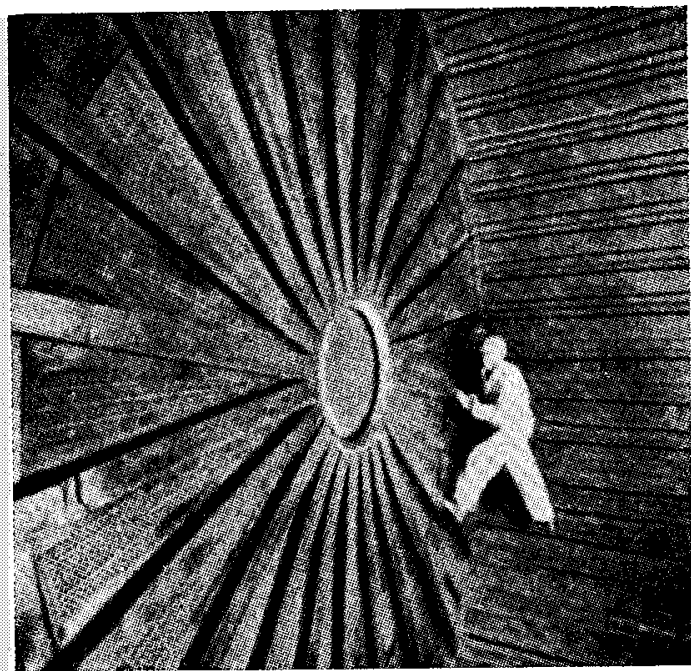

Fig. 4.-Pared de desearga de un molino de guijarros de $5,9 \mathrm{~m} \varnothing \times 6,2 \mathrm{~m}$ de longitud.

La experiencia con unos 300 blindajes de caucho ha puesto de manifiesto que una distancia entre las barras elevadoras de unos $300 \mathrm{~mm}$ frena mejor el material y no empeora más el efecto de moler que si se emplea una distancia mayor. De esta distancia de $300 \mathrm{~mm}$ resulta una excelente rentabilidad del blindaje de caucho.

Los tabiques con cribas de caucho en molinos con rejilla (fig. 4) y los tabiques de separación en molinos con varias cámaras son, en muchos casos, mejores que los equivalentes metálicos. Cuando las perforaciones están bien realizadas y dimensionadas, no se produce obstrucción alguna en los agujeros de paso. La resistencia extraordinaria de la goma al desgaste hace que la superficie del tamiz se conserve durante mucho tiempo y que no pasen granos demasiado grandes.

Otra ventaja importante empleando blindajes de goma, es la amortiguación del ruido. La figura 5 muestra el nivel de ruido, expresado en decibelios, de un molino blindado con placas de acero al manganeso y en la figura 6 se puede ver el nivel de ruido del mismo molino blindado con goma. Según H. C. Hardy (J. Acoustical Soc. of America 1957, 756, tomo 24), las intensidades del sonido por encima de la zona rayada hacen daño al oído. Por debajo de esta zona no hay ningún peligro. La zona rayada marca el límite.

\section{EXPERIENCIAS DE LA PRACTICA}

En una mina de hierro se instaló un blindaje de goma en un molino primario, con las mismas distancias entre las barras elevadoras que en el primitivo blindaje de acero (fig. 7). 
Fig. 5.-Nivel fónico de un molino con blindaje de acero.

Fig. 6.-Nivel fónico de un molino con blindaje de caucho.

DATOS DEL MOLINO:

$$
\begin{gathered}
\text { - dimensiones : } \\
\text { - elementos de } \\
\text { molienda: } \\
\text { - material de } \\
\text { alimentación } \\
\\
\text { - rendimiento } \\
\text { del molino: }
\end{gathered}
$$

\begin{tabular}{|c|c|c|c|c|c|c|c|c|}
\hline PUNTO DE MEDIOA & $20-75$ & 75.150 & $50-300$ & $500-609$ & $\begin{array}{l}600 \\
1200\end{array}$ & $\begin{array}{l}1200 \\
2400\end{array}$ & $\begin{array}{l}2400 \\
4000\end{array}$ & $\begin{array}{l}4600 \\
10000\end{array}$ \\
\hline ANTHAMA & 94 & 98 & 97 & 97. & 91 & 87 & 79 & 72 \\
\hline DERTHO & 98 & 97 & 9 & 103 & 100 & 97 & 9 & 74 \\
\hline CEL MOL INO - & 9 & 90 & 98 & 102 & 98 & 92 & 86 & B) \\
\hline
\end{tabular}

\begin{tabular}{|c|c|c|c|c|c|c|c|c|}
\hline PUNTO DE MEDIDA & $20-75$ & $75-150$ & $150 \cdot 300$ & $300-600$ & $\begin{array}{l}600 \\
1200\end{array}$ & 2700 & $\begin{array}{l}2400 \\
4800\end{array}$ & $\begin{array}{l}4800 \\
10000\end{array}$ \\
\hline $\begin{array}{l}\text { ENTRABA } \\
\text { AL MOLINO }\end{array}$ & 87 & 91 & 90 & 90 & oI I & 80 & 69 & 64 \\
\hline $\begin{array}{l}\text { CENTRO } \\
\text { DEL HOLNO - }\end{array}$ & 92 & 93 & 92 & 94 & $8 \theta$ & 73 & 70 & 69 \\
\hline BEL MOLA INO - & 88 & 89 & 92 & 91 & 87 & 74 & 67 & 66 \\
\hline
\end{tabular}


A consecuencia de la gran distancia existente entre los agujeros de la carcasa del molino, hubo que reforzar las placas con unos tirantes recubiertos de caucho vulcanizado 
que tenían el mismo perfil que el de las barras elevadoras fijadas elásticamente. Estos tirantes en las placas del revestimiento estaban ya casi gastados por completo después de 1.500 horas de uso. En las barras elevadoras elásticas, sin embargo, sólo los bordes agudos estaban redondeados por el desgaste.

Fig. 7.-Blindaje de caucho con barras longitudinales recubiertas de caucho sobre la placa del revestimiento.

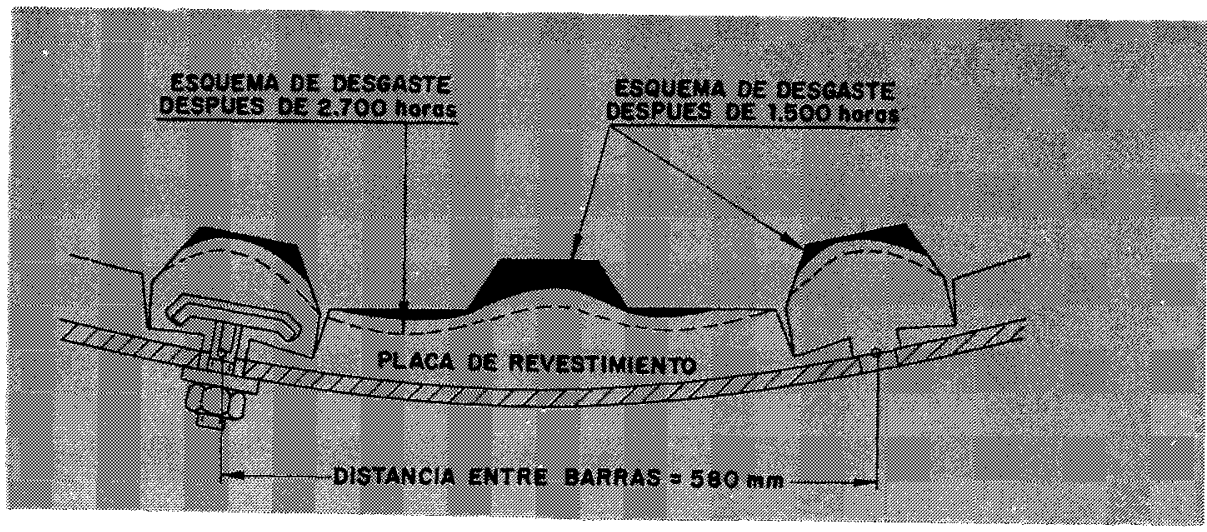

Este desgaste de las barras elevadoras aumentó mucho, aproximadamente unos $12 \mathrm{~mm}$, con 1.000 horas más de uso.

Más tarde se revistió este molino con doble cantidad de divisiones, es decir, las barras longitudinales recubiertas de caucho y hasta ahora fijas se cambiaron por barras elevadoras elásticas. Las mediciones del desgaste realizadas hasta la fecha demuestran que así puede multiplicarse su duración.

En esta misma mina de hierro se instaló otro molino blindado con goma con una distancia menor entre agujeros de sujeción, es decir, con división $\pi($ distancia $=314 \mathrm{~mm})$. De la figura 8 puede deducirse la gran reducción en el desgaste y la extraordinaria rentabilidad.

DATOS DEL MOLINo:

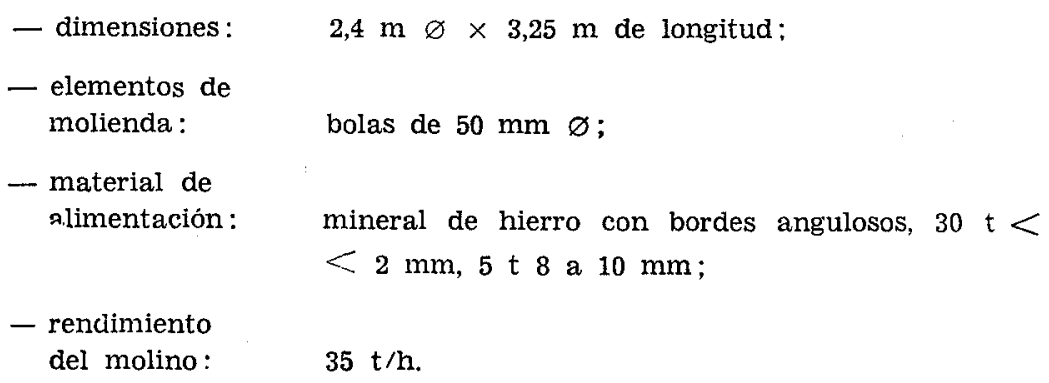

Fig. ४.-Fijación elástica de las barras elevadoras de un blindaje de caucho con distancia entre ba. rras $314 \mathrm{~mm}$.

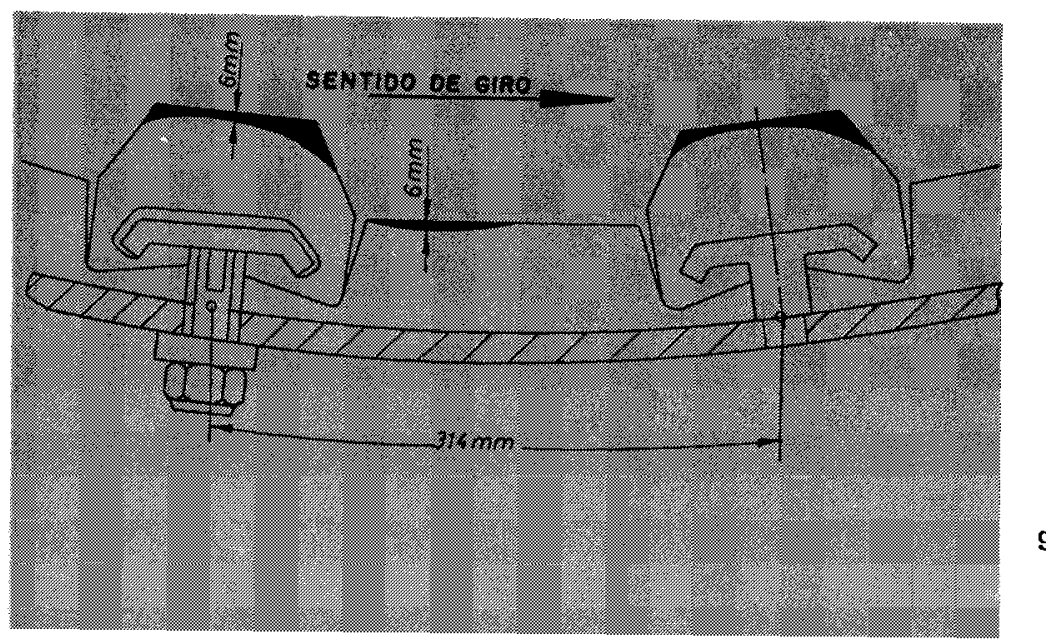


Este molino empezó a funcionar en septiembre de 1964. Después de 8.300 horas de uso, en el mes de diciembre de 1965, el desgaste del blindaje de goma era de $6 \mathrm{~mm}$ como máximo. Esto corresponde a un desgaste total de unos $103 \mathrm{~kg}$ de goma. Esto demuestra que el blindaje de goma durará por lo menos unas 40.000 horas. Los blindajes anteriores de acero al manganeso, después de 8.000 horas de uso como máximo, estaban completamente desgastados. Durante este tiempo se produjo una pérdida de unos $11.000 \mathrm{~kg}$ de acero al manganeso. El peso de la chatarra era de unos 5.000 kilogramos.

El precio de los dos revestimientos exa prácticamente el mismo, lo cual demuestra la gran rentabilidad. El cálculo realizado hasta ahora pone de relieve que el blindaje de caucho facilita un ahorro de aproximadamente 155.000 marcos, o sea, de unos 34.000 marcos al año.

En una fábrica de hormigón celular se blindó con caucho un molino tubuiar a fines de diciembre de 1965.



Después de un funcionamiento de 5.331 horas de uso tuvo iugar una inspección meticulosa del molino.

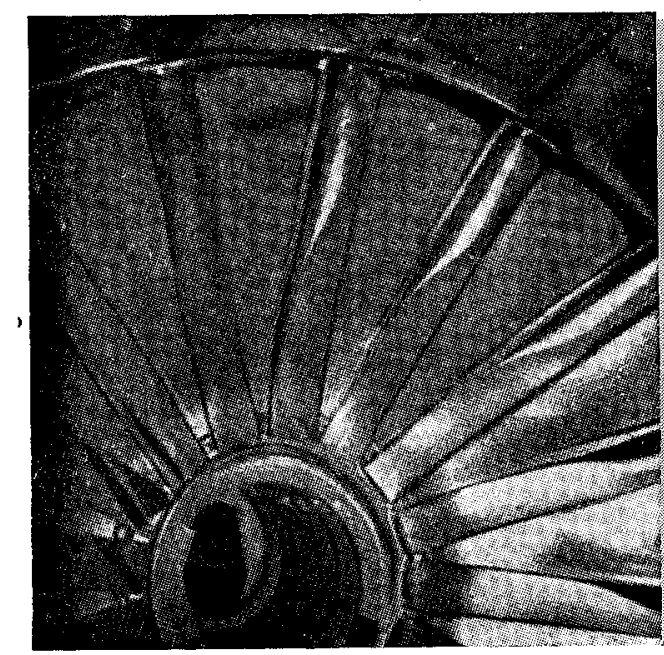

Fig. 9.-Pared de entrada de un molino con blin. daje de caucho, después de 5.331 horas de servicio.

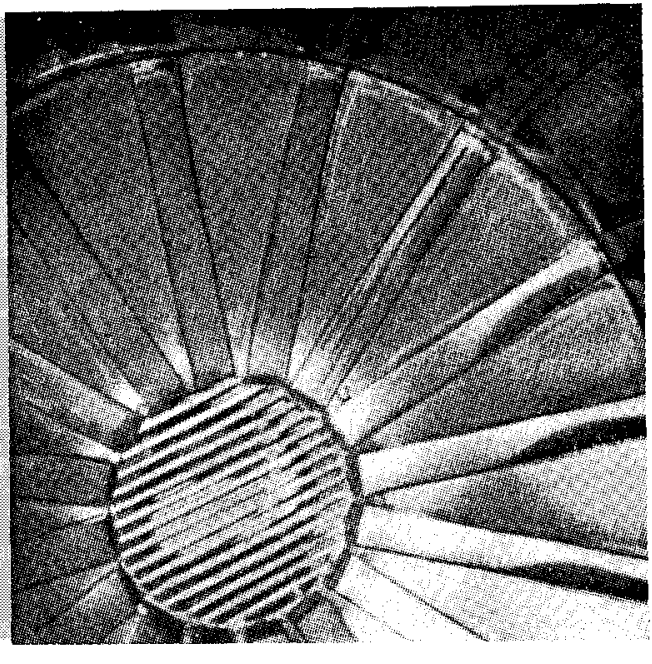

Fig. 10.-Pared de desearga de un molino con blindaje de caucho, después de 5.331 horas de servicio.

El blindaje de la pared frontal a la entrada del molino mostró un desgaste muy leve de las placas. El desgaste era de 2 a $3 \mathrm{~mm}$ solamente. La pérdida en las barras elevadoras era más grande; éstas estaban más desgastadas en los alrededores del eje que en la periferia de dicha pared frontal (fig. 9). 
Por la forma del desgaste de las barras elevadoras se observa claramente el sentido de giro del molino.

El estado de las barras elevadoras permite emplearlas un año más, antes de tener que darles vuelta en su posición radial.

Como era de esperar, en los segmentos de relleno del blindaje de la pared frontal no se ha producido un gran desgaste.

El revestimiento de la pared frontal en la salida del molino presenta un cuadro de desgaste parecido al de la entrada (fig. 10).

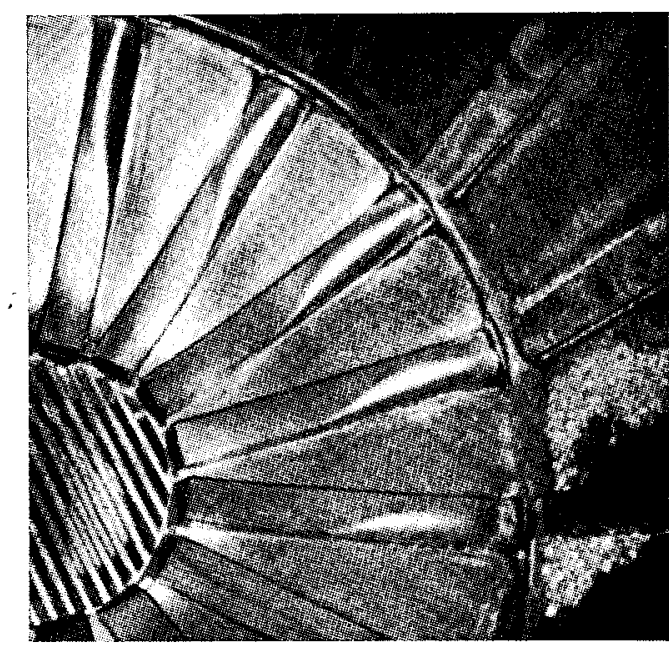

Fig. 11.-Desgaste de barras elevadoras en la pared de descarga, después de 5.331 horas de trabajo.



Fig. 12.-Desgaste del blindaje periférico, después de $\mathbf{5 . 3 3 1}$ horas de servicio.

El desgaste de las placas de relleno es de $3 \mathrm{~mm}$ como máximo; el de las barras elevadoras, que soportan dichas placas, es, sin embargo, contrario al de las de la pared del frente de entrada. Estas últimas sólo están desgastadas en el tercio extremo, mientras que hacia la abertura de salida apenas tienen desgaste (fig. 11).

El panorama de desgaste de las barras elevadoras de la pared del frente de salida, en general, es mejor que el de las barras elevadoras del frente de entrada. Sin embargo, también estas barras pueden seguir trabajando un año más, hasta que haya necesidad de darles la vuelta.

El desgaste en los segmentos de relleno en la pared del frente de salida es también muy reducido.

El porqué las barras elevadoras en la pared frontal de la descarga se desgastan más en los extremos, y las de la pared del frente de entrada muestran su mayor desgaste en el tercio interior, lo explicará el flujo del material dentro del molino. El material se mueve bastante deprisa desde la pared de entrada a la pared de salida y se acumula en ésta hasta que sea posible su salida por la boca de descarga. 
El blindaje de la carcasa envolvente muestra asimismo un cuadro de desgaste muy favorable. Por razones técnicas, en este molino se emplearon barras elevadoras altas y bajas, alternativamente, y, como es natural, el desgaste en las barras altas es mayor. En la figura 12 se representa el desgaste de las barras elevadoras altas y bajas, hasta el momento.

Este desgaste, visto a lo largo del eje del molino, es casi igual en todo él. En la figura 13 se puede apreciar que las barras elevadoras de envoltura, en las paredes de los frentes de entrada y salida apenas están gastadas.

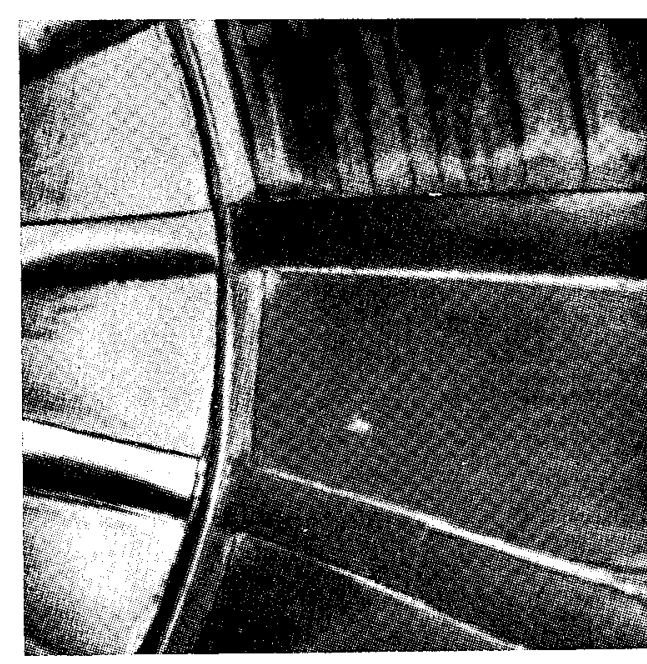

Fig. 13.-Pequeño desgaste de las barras elevadoras en la zona del tabique de entrada, después de 5.331 horas de trabajo.

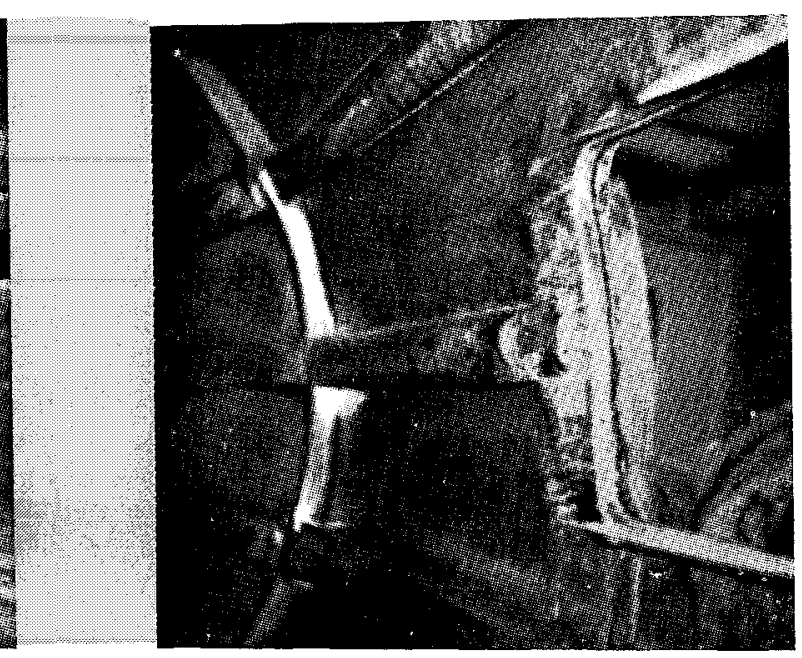

Fig. 14.-Desgaste del blindaje de caucho alrededor del agujero de hombre, después de 5.331 horas de servicio.

Los dos tipos de barras elevadoras se han conservado tan bien que su vuelta, por razones técnicas del funcionamiento, todavía no es necesaria.

Mas como a la dirección de la empresa le convenía evitar una posible interrupción en el funcionamiento de la fábrica en la temporada interesante, se anticipó la vuelta de las barras elevadoras, por mera precaución.

El desgaste en las placas de la carcasa era de $6 \mathrm{~mm}$ como máximo. Llama la atención el hecho de que el desgaste de las placas delante de una barra elevadora alta es mayor que delante de una barra elevadora baja. Esto se explica por un cierto efecto de pala de las barras elevadoras altas.

En la figura 12 puede verse el desgaste de una placa de la carcasa a la salida del molino, pero no en la pared frontal.

Por regla general, el desgaste de las placas de la generatriz del molino es casi igual en toda su extensión (fig. 14). A tono con este desgaste, las placas duran por lo menos tanto tiempo como dos series de barras elevadoras.

Por último puede decirse que el grado de desgaste de este blindaje de goma es muy satisfactorio, sobre todo teniendo en cuenta que en este molino un revestimiento de fun- 
dición de superficie endurecida se agotaba después de 1.500 horas de uso como máximo. Después de 5.331 horas de uso, el revestimiento de goma ya ha trabajado tres veces más, y con las barras elevadoras usuales llegará a durar hasta siete veces más. Entonces, sólo será necesario, quizás, cambiar las barras elevadoras del revestimiento de la carcasa. Con las placas del primer equipo instalado puede consumirse por lo menos una serie más de barras elevadoras nuevas, con lo cual resulta que este proceso de molienda es muy rentable en cuanto a los costes.

Las placas de las paredes frontales duran, por lo menos, tanto tiempo como las placas de la carcasa, y las barras elevadoras en las paredes de carga y descarga sólo hay que darles la vuelta después de unas 11.000 horas de uso.

En un molino tubular por vía húmeda de una fábrica de cemento se instalaron, en el mes de enero de 1965, placas de salida periféricas de caucho con agujeros de paso de $6 \times 15$ milímetros.

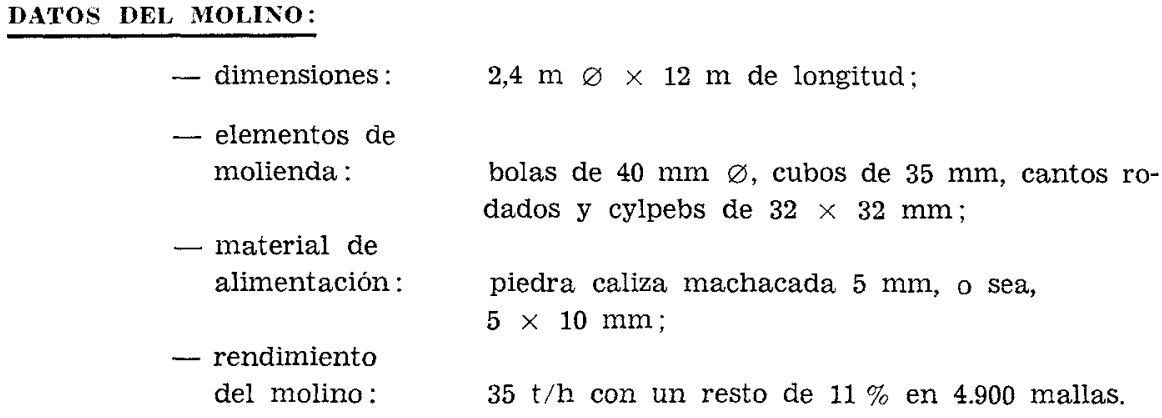

Fig. 15.-Placas de desearga periférica en caucho, durante la instalación de un molino que trabaja en húmedo de $2,4 \mathrm{~m} \varnothing \times 12 \mathrm{~m}$ de longitud.

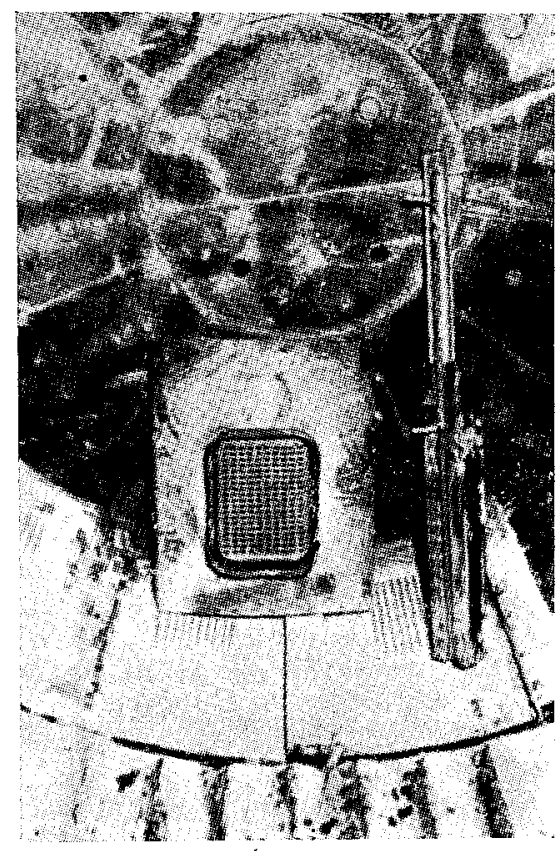

La figura 15 muestra estas placas periféricas de salida durante el montaje. En la placa destacada en la parte superior se observa su construcción por la parte posterior. En las placas con rejilla de acero empleadas hasta ahora, los agujeros de salida había que limpiarlos una o dos veces en cada turno durante el primer semestre después de la instalación, y después, según el desgaste, una vez al día. 
Como los agujeros en las placas de caucho se limpian solos por su elasticidad, pueden ahorrarse considerables gastos.

En el mes de marzo de 1964, se revistió con un blindaje de caucho un molino tubular nuevo trabajando por vía húmeda.

\section{DATOS DEL MOLINO:}

$\begin{array}{ll}\text { - dimensiones: } & 1,6 \mathrm{~m} \varnothing \times 3,3 \mathrm{~m} \text { de longitud; } \\ \text { - elementos de } & \\ \text { molienda: } & \text { barras de } 80 \mathrm{~mm} \varnothing \text { como máximo; } \\ \text { - material de } & \\ \text { alimentación: } & \text { grava de morrena de } 12 \text { a } 30 \mathrm{~mm} ; \\ \text { - rendimiento } & \\ \text { del molino: } & 12 \text { o } 14 \mathrm{t} / \mathrm{h} .\end{array}$

Se inspeccionó el blindaje después de 3.230 horas de uso. El estado de desgaste del mismo puede considerarse como muy satisfactorio, sobre todo teniendo en cuenta que se trata de moler un material abrasivo y con mucho contenido de cuarzo.

El desgaste de los nervios elevadores es mayor en las zonas de entrada y salida del molino que en la zona central. Como es natural, dichos nervios elevadores tienen un desgaste mayor en el lado de ataque de la carga, pero, a pesar de ello, todavía están en bastante buenas condiciones como para trabajar con plena eficacia. Debido a esto no hay motivos de reposición de las barras elevadoras en un futuro próximo, por lo menos considerando razones técnicas de molienda. No obstante, desde el punto de vista del desgaste, la situación ya no es tan fácil; parece que al aumentar el desgaste en las barras elevadoras también aumenta en las placas de envoltura colocadas entre ellas, de manera que quizás se piense en cambiar relativamente pronto las barras elevadoras desgastadas.

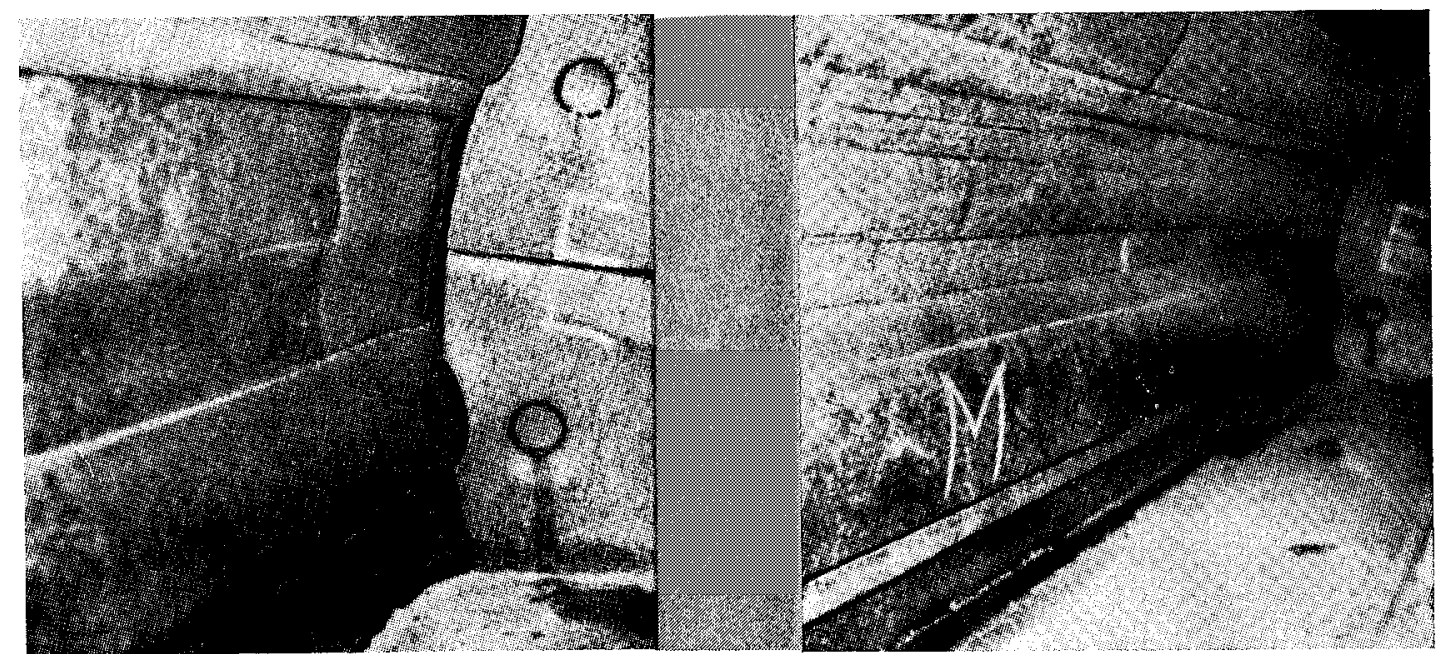

Fig. 16.-Molino de barras con blindaje de caucho, después de 3.230 horas de trabajo, en la zona de entrada.
Fig. 17-Molino de barras con blindaje de cauchu, después de 3.230 horas de servicio, en la zona central.

La situación del desgaste en la entrada puede apreciarse claramente en la figura 16. 
El estado de desgaste en el centro del molino se observa en la figura 17 y la situación correspondiente a la salida del molino se representa en la figura 18.

El estado exacto de desgaste del blindaje de caucho se expone en los cortes de perfil de la figura 19; estos cortes del perfil se hicieron en la entrada, en la salida y a ciertas distancias de la entrada del molino. En la figura se comparan estos perfiles con los perfiles nuevos. La zona rayada corresponde al desgaste.

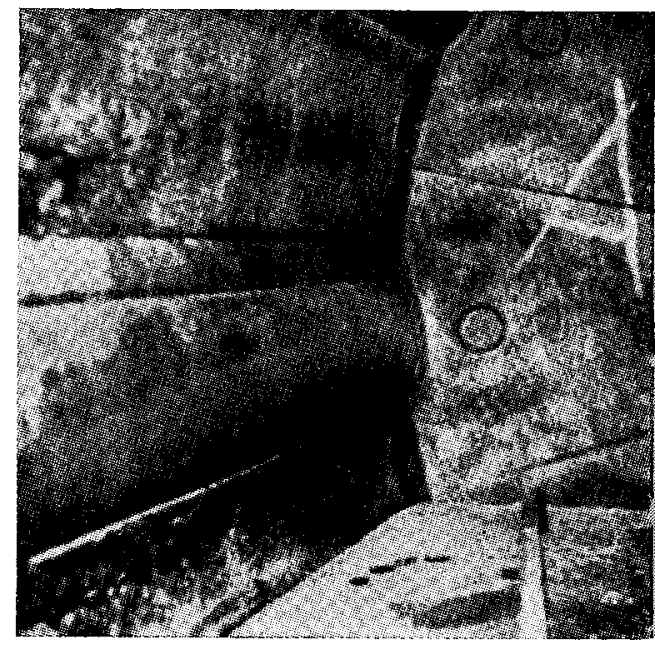

Fig. 18.-Molino de barras con blindaje de caucho. después de 3.230 horas de servicio, en la zona de descarga.

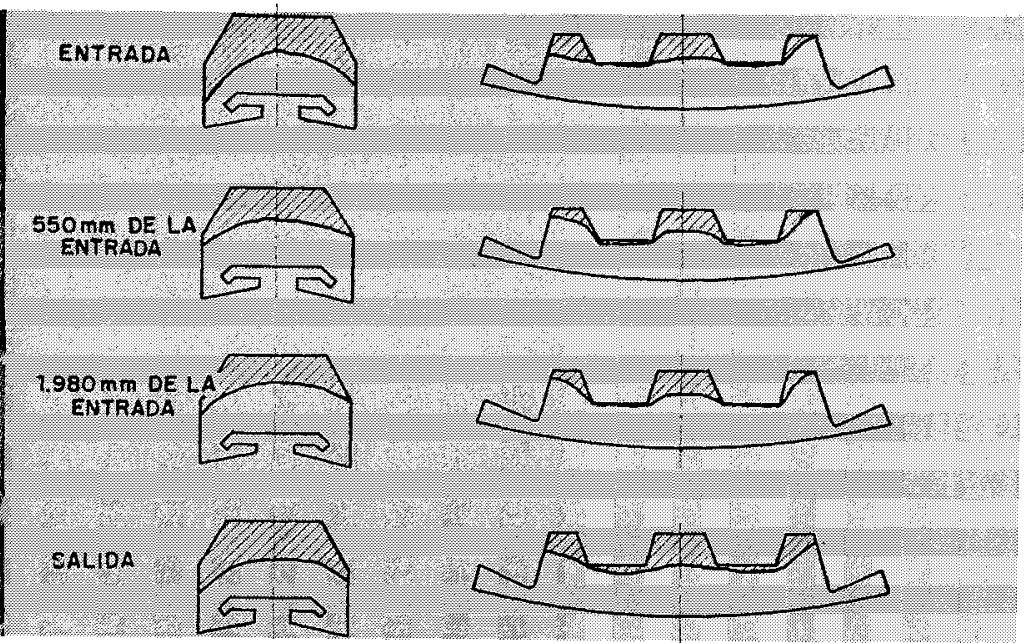

Fig. 19.-Estado de desgaste de las placas de blindaje periféricas y de las barras elevadoras, después de 3.230 horas de trabajo.

Se observará que el desgaste es más grande en la entrada y en la salida del molino. Llama la atención, sin embargo, la gran diferencia de desgaste entre la placa de revestimiento y la barra elevadora a la entrada y salida del molino, por un lado, y el centro del molino, por otro. Hay que añadir que la zona de gran desgaste en la entrada y salida del molino sólo tiene de 250 a $300 \mathrm{~mm}$ de longitud; más tarde sigue una zona de transición, de unos $300 \mathrm{~mm}$, que conduce al buen perfı encontrado en las placas de la zona céntrica del molino.

Las barras elevadoras fueron cambiadas después de 4.000 horas de uso. En la figura 20 se observa el estado de desgaste de las barras elevadoras después de este tiempo de trabajo.

En el mes de marzo de 1966 se instaló un blindaje de caucho en un molino tubular nuevo trabajando por vía húmeda con estrechamiento en la boca de descarga, que más tarde fue empleado en una instalación de áridos en el Danubio.

DATOS DEL MOLINO:

$\begin{array}{ll}\text { - dimensiones: } & 1,6 \mathrm{~m} \varnothing \times 3,0 \mathrm{~m} \text { de longitud; } \\ \text { - elementos de } & \text { barras de } 2.870 \mathrm{~mm} \text { de longitud y de } 30 \mathrm{a} \\ \text { molienda: } & 95 \mathrm{~mm} \varnothing ; \\ \text { - material de } & \text { grava del Danubio machacada } 5 \text { a } 15 \mathrm{~mm} ; \\ \text { alimentación: } & \\ \text { - rendimiento } & \\ \text { del molino: } & 10 \mathrm{~m}^{3 / \mathrm{h} .}\end{array}$


Se inspeccionó este molino en cuanto a su desgaste después de 1.469 horas de uso; se molió canto rodado del Danubio, de 5 a 7 y 7 a $15 \mathrm{~mm}$, en proporciones iguales aproximadamente a arena de 0 a $3 \mathrm{~mm}$. Este material, a consecuencia de su composición, es muy abrasivo (gran contenido de cuarzo, gran dureza y, en gran parte, resistencias a la compresión de hasta $5.000 \mathrm{~kg} / \mathrm{cm}^{2}$ ), lo que hay que tener en cuenta al considerar el desgaste.

Fig. 20.-Barras elevadoras de caucho usadas, desmontadas de un molino de barras, después de 4.000 horas de servieio.

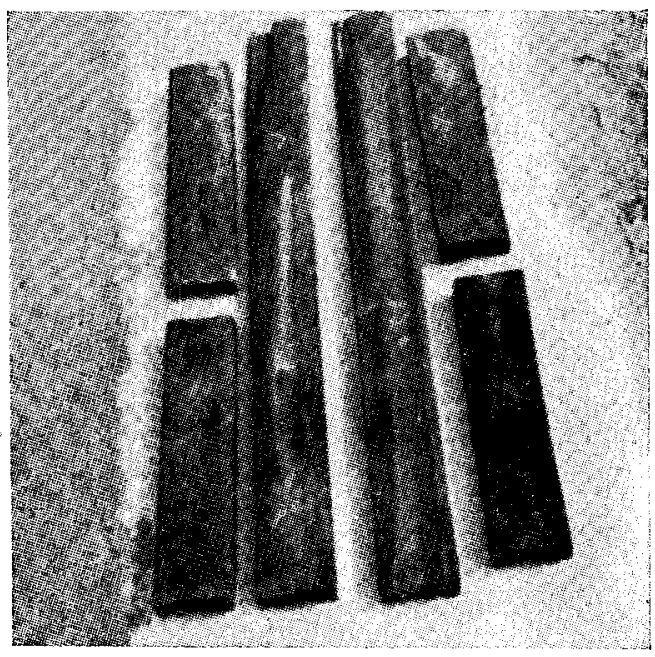

En las primeras 1.182 horas de uso, el molino tenía un grado de llenado de sólo un $25 \%$. Este grado de llenado demasiado bajo lleva consigo, además de un rendimiento muy reducido, un mayor desgaste del blindaje de caucho y de las barras molturadoras, porque el paquete de elementos de molienda demasiado pequeño tiende a resbalar.

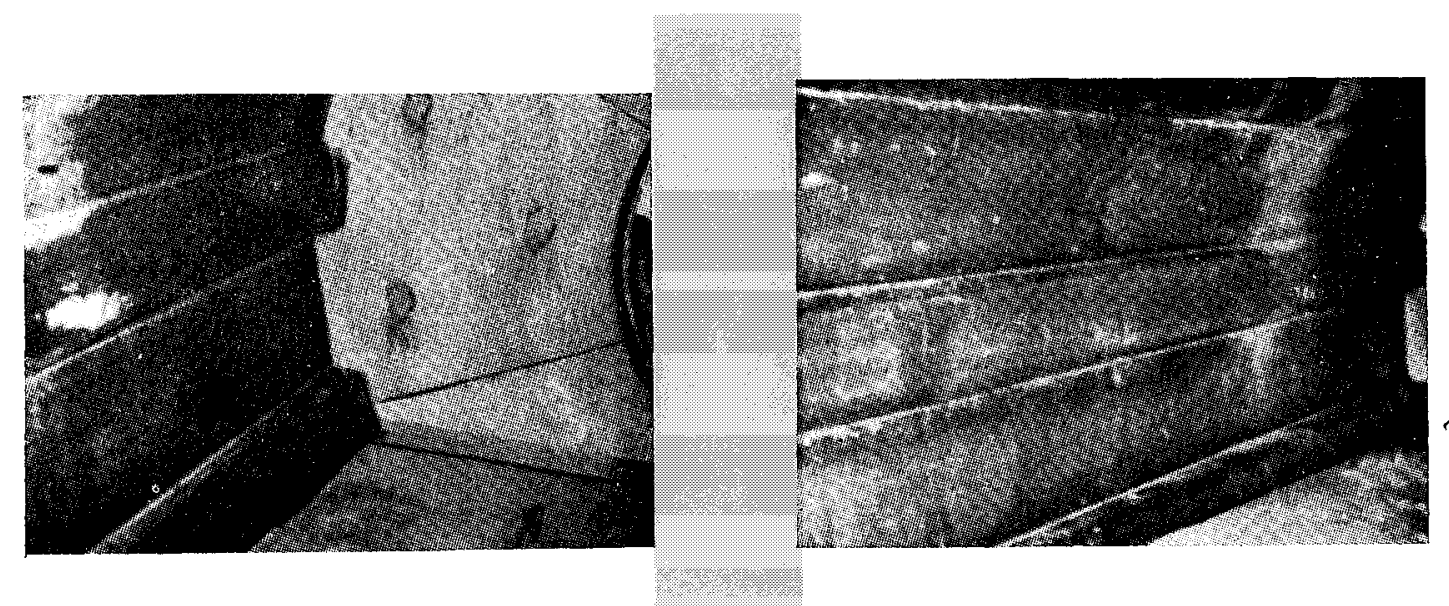

Fig. 21.-Molino de barras con blindaje de caucho, después de 1.469 horas de trabajo, vistas del lado de inmersión o ataque de las barras elevadoras.
Fig. 22.-Molino de barras con blindaje de caucho, después de 1.469 horas de servicio, vistas del lado de inmersión de las barras elevadoras, en el centro del molino. 
Como era de esperar, el desgaste del revestimiento en la entrada y salida del molino era mayor que en el centro. El mayor desgaste se produjo en la salida, lo mismo que en los molinos tubulares de barras revestidos con acero. Este resultado es válido tanto para las barras elevadoras como para las placas de revestimiento.

La figura 21 muestra el borde de ataque o inmersión de las barras elevadoras. Estas se han desgastado unos $15 \mathrm{~mm}$ y las placas unos 12 milímetros.

La figura 22 indica análoga situación en el centro del molino. En éste el desgaste del revestimiento es el más reducido.

La figura 23 reproduce el estado de desgaste a la entrada del molino. Aquí llama la atención el hecho de que el desgaste ha progresado más a una distancia de 50 a $250 \mathrm{~mm}$ de la pared frontal. Esto se aprecia muy bien en la figura 24.

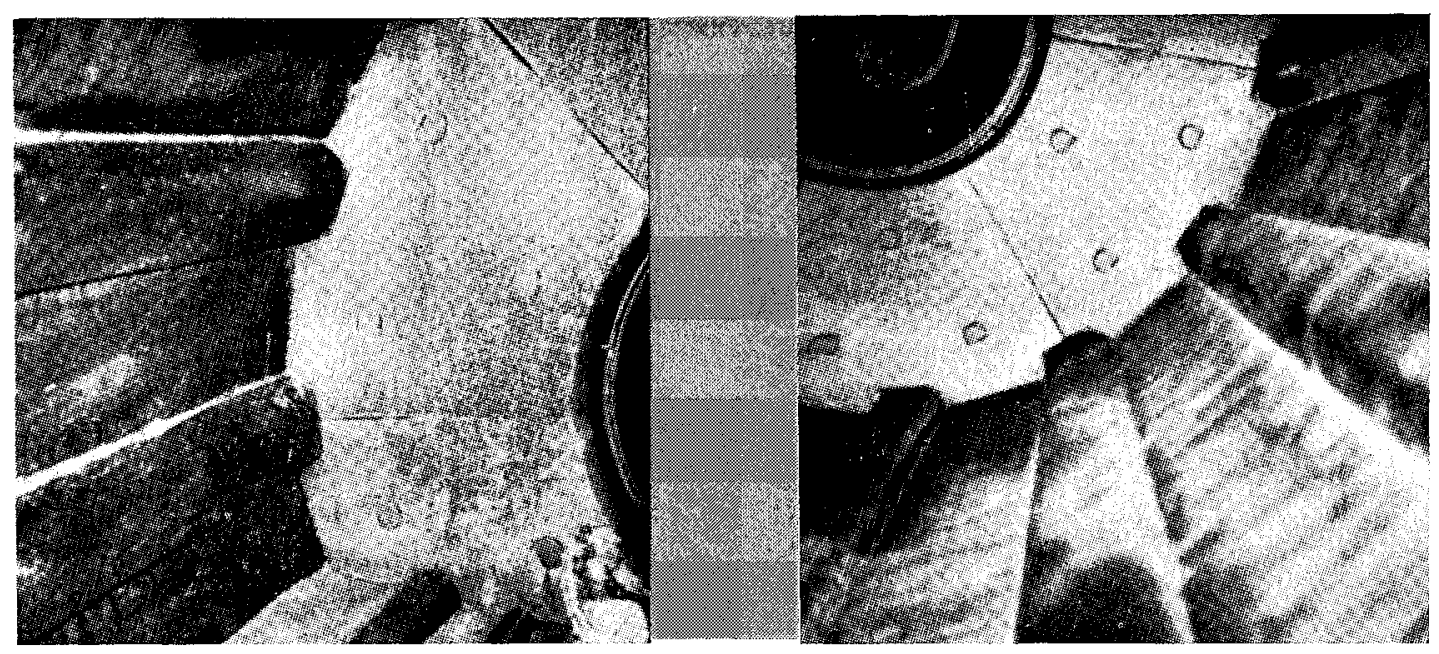

Fig. 23.-Molino de barras con blindaje de caucho. después de 1.469 horas de servicio, en el lado de entrada del molino.
Fig. 24.-Molino de barras con blindaje de caucho, después de 1.469 horas de servicio, en el lado de entrada del molino.

Este proceso se explica por el hecho de que las barras molturadoras son unos $50 \mathrm{~mm}$ más cortas que el espacio libre de molienda y que se trasladan hacia la salida; por esto el material de revestimiento toca las barras molturadoras a partir del sitio antes mencionado. El mayor desgaste en la zona de $250 \mathrm{~mm}$ se produce por el material con bordes extraordinariamente agudos, que en esta zona sufre prácticamente una trituración antes de que empiece el verdadero proceso de molienda.

Teniendo en cuenta que el tipo de material fomenta el proceso de desgaste extraordinariamente, puede decirse que el estado de conservación de este blindaje con envoltura de caucho es muy favorable. En otras instalaciones de áridos, los blindajes de acero duro al manganeso duran sólo unas 700 a 900 horas de uso.

Con el desgaste actual, las barras elevadoras han de ser vueltas aproximadamente a fines de 1967. De momento todavía no se puede decir qué duración máxima pueden alcanzar estos blindajes. 